\title{
Observations on earth currents in lines a kilometre in length, and their comparisons with magnetic variations
}

\section{H. Wild}

To cite this article: $\mathrm{H}$. Wild (1884) Observations on earth currents in lines a kilometre in length, and their comparisons with magnetic variations, Philosophical Magazine Series 5, 17:109, 559-562, DOI: $10.1080 / 14786448408627557$

To link to this article: http://dx.doi.org/10.1080/14786448408627557

曲 Published online: 29 Apr 2009.

Submit your article to this journal $₫$

Џll Article views: 2

Q View related articles $₫$ 
reach so far north as Richmond. The presence of pervious beds of the New Red may possibly be found to compensate in some degree for the absence of the Neocomian as a source of water-supply.

(3) The discussion of these facts throws some new light on the problem of the existence of Coal-bearing strata at workable depths under London. Small particles of anthracite were found in several of the deeper beds at Richmond, these being probably derived from Coal-seams in the great Palæozoic axis; but the presence of Jurassic and Triassic strata shows that a greater thickness of strata will probably have to be pierced in order to reach the coal than was formerly supposed.

The paper concludes with some notes on the very interesting and beautifully preserved fossils from the Great Oolite beds under London.

\section{Intelligence and Miscellaneous Articles.}

OBSERVATIONS ON EARTH CURRENTS IN LINES A KILOMETRE IN LENGTH, AND THEIR COMPARISONS WITH MAGNETIC VARIATIONS. BY H. WILD.

THE International Congress of Electricians which met in Paris 1 from the 16 th to the 26 th October, 1882, formulated the following resolutions among others :-

"It hopes that certain lines, even of small length, independent of the general telegraph system of each country, will be exclusively devoted to the investigation of earth currents."

Thanks to the kindness of the Directorate of Russian Telegraphy, the Meteorological and Magnetic Observatory of Paulowsk has already, since the month of. August 1882, been in possession of two submarine lines, each a kilometre in length, one being perpendicular and the other parallel to the magnetic meridian. Each of these lines is connected with an aperiodic galvanometer set up in the underground pavilion for observing magnetic variations; so that the readings of the scale may be made at the same time as those of the varjation instruments. The Observatory of Paulowsk was thus in a position to realize the hope of the Congress ; and earth currents have been regularly observed in these two lines during the period of the Polar Expedition (that is, from the 1st of September 1882 to the 1st of September 1883) three times a day, and on the special days of observation every five minutes for twenty-four hours.

In a paper (Mémoires de l'Acad. imp. des Sc. de St. Pétersbourg, vol. xxxv. No. 12) I described in detail the method of observation which I used in these researches. I particularly dwelt on the difficulty which arises in these short lines from the different electromotive force of the electrodes ; so that we must distinguish clearly between the earth current properly so called, which bifurcates in the lines by the electrodes (or earth plates), and the currents which are only due to the electrical difference of these plates. By 
combining, in varions ways, the four electrodes of our two lines, I succeeded in separating the two classes of currents, and in drawing from my observations the following conclusions:-

(1) The difference in the electrical potential of the earth for two points at a distance of 1 kilometre, and in the most favourable direction, is in any case less than 0.001 volt for a time of magnetic calm-that is to say, free from magnetic disturbances; while the difference of the electronotive force of the electrodes may reach 0.05 volt. During magnetic storms the earth currents become stronger; but even then their potential rarely exceeds this latter limit, $0 \cdot 05$, in lines a kilometre in length.

(2) The electromotive difference of the electrodes placed at a depth of 2 metres below the surface, and connected by well-insulated wires, is for some time so constant that we may look upon any appreciable change in the ordinary current due to the electrudes as the manifestation of an earth current properly so called.

(3) The ratio between the force of the branch earth current and of the current due to the electrodes is independent of the resistance of the lines and of the dimensions of the electrodes, and only increases with the distance of these latter. In order to be certain about an observation of an earth current properly so called during a time of magustic calm, if indeed an earth current does exist at such periods, the lines should be 50 kilometres in length. Only by using earth plates more uniform than they are usually, is it possible to observe this current in shorter lines, that is 1 kilometre in length.

(4) The resistance of the earth for electrodes a metre square and at a distance of 1 kilometre, is equal to from 30 to 60 ohms. Assuming that the total resistance of the circuit, including the galvanometer, does not exceed 100 obms, we could observe earth currents in such lines by means of a mirror-galvanometer, in which the value of a division of the scale is equal to 0.000002 ampère. The deflections by earth currents will rarely exceed \pm 250 parts of the scale even during magnetic storms.

Since the publication of the paper mentioned, the calculation of the observations made regularly during the period from September 1882 to September 1883 bas been so far advanced as to enable me to communicate to the Academy some interesting results which I have deduced from them :-

1. The earth-current at Paulowsk in our lines of one kilometre in length is usually manifested not as a current which flows for some time in a certain direction, and the force of which varies slowly, but as more or less strong alternating currents, which change rather rapidly their direction in space.

2. The component of the earth current which appears in the E.-W. line is generally stronger than that observed in the N.-S. line; the direction approaches therefore the parallels rather than the meridians.

3. The observations of the term-days, taken separately each day, 
do not show a daily course of the earth current either in respect of magnitude or number of oscillations. But taking the mean of 24 term-days, a sufficiently distinct, though small, daily course is seen. The current in the S. $-\mathrm{N}$. line indicates a maximum between 4 and 5 o'clock in the morning, and a minimum at 8 o'clock in the evening; and the current in the W.-E. line a maximum at 8 A.M., and a minimum at l P.M. The amplitude of this oscillation is very small, only corresponding for the two components to about 0.0008 volt. This variation does not coincide with the normal pariation of the magnetic elements; and it follows that the daily variation of the earth currents cannot be regarded as the origin of the daily variation of the unagnetic elements.

4. As soon as the earth current shows itself in the two lines with greater force, the magnetic instruments begin to diverge from their regular course; and these disturbances increase in general with the strength of the earth currents without there being any strict proportionality between the two classes of phenomena. On the 15th of November, 1882, for instance, the earth currents showed themselves in greater strength in the two lines than ou the 1st of March, 1883; and nevertheless the course of the magnetic instrument on the first of these days was far more irregular than on his latter day.

5. If, as Sir G. Airy has already done for similar observations at the Greenwich Observatory, we compare the current in the S. $-\mathrm{N}$. line with the changes in the declination, and the current in the W.-E. line with the changes in horizontal intensity, we often find, especially for somewhat slow changes, perfect equality between these two kinds of disturbances; but the variation of the current always precedes that of the earth's magnetism by at least five minutes, so that the current appears as the primary cause of this latter. Thus the motion of the magnetic apparatus is always that which would be required by the fundamental law of electromagnetism, if the earth current had a direct influence on the magnets. If, for instance, a positive current from north to south shows itself in the N.-S. line, the easterly declination of the needle increases at the same time; and if in the E.-W. line a positive current goes from east to west, the horizontal intensity of terrestrial magnetism becomes greater - that is to say, the north pole of the bifilar moves towards the north.

The retardation which the indications of the magnetic instruments experience relatively to those of the galvanometer could be explained by the hypothesis that the earth current, which directly influences the magnets of the galvanometers, only acts on the variation instruments by the magnetization of the more or less thick layers of earth, and this requires a certain time.

6. This retardation in the effects of the earth current explains, partially at any rate, the want of strict proportionality between the variations of the current and the magnetic elements. It is observed that the proportionality fails particularly when the changes in the current are very frequent and alternating; and it is more 
complete on those days on which the disturbances are not sudden. Now it will be readily understood that in the former case the transitory currents in opposite directions which rapidly succeed each other, will be partially destroyed by the magnetization of the earth, so that the variations of the magnetic instruments will be relatively smaller. The observations of the 15th November, 1882, and of 1st March, 1883, as well as the curves registered by the magnetograph, support this explanation. The curves registered on the lst of March show by the clearness of the lines a relatively tranquil course of the magnets, although the slow disturbances have been somewhat large; and, in consequence, the curves drawn from the readings of the galvanometers are not very marked, and those of the S.-N. current are very similar to the curves of the unitilar, while those of the E.-W. current are in close agreement with the registrations of the bifilar. On the other hand, the two kinds of curves of November 15 show little agreement with each other; and although the variations of the two currents are very great and very rapid, the registers of the magnetograph, as well as the direct observations of the magnetic instruments, do not show great perturbations; but if we examine more closely the curves registered, we easily observe the traces of a permanent oscillation of magnets within small limits.

We may then conclude that earth currents are always the primary cause of magnetic storms, but not of the periodical variations of the magnetic elements.

Observations on earth currents in the telegraph lines of Austria, which Director Müller of Pola has kindly communicated to me, show that in long lines also the earth current is seen in the same way as in our very short lines-that is to say, a a rapid series of alternating currents. It follows from this, that earth currents at the time of magnetic storms are usually currents of induction and discharge; this is entirely in harmony with the connexion between these storms and auroræ boreales, which the experiments of $M$. Lemströrn entitle us to consider as discharges of atmospheric and terrestrial electricity.

Unfurtunately the observations of earth currents in some of the longer Russian telegraph lines, which were projected for the epoch of the Polar expeditions, have not been made. It was therefore not possible for me to compare the observations of our short lines with those of the longer ones starting from the same point, so as to learn how far the currents of the two kinds of lines are in agreement. But as in any case the telegraph lines could only have been at our disposal for a short time, and as there are as yet no underground lines in Russia, I think for the present it would be more useful for such comparisons to have at our disposal lines in all respects similar to those a kilometre long which we already have, but five to ten times as long.-Bulletin de l'Académie des Sciences de St. Pétersbourg, December 11, 1883. 


\section{ON THE ABSOLUTE STANDARD OF LIGHT. BY PROF. J. VIOLLE.}

The investigation of the radiation emitted by melted silver had essentially for its object the verification of the principle of that method which consists in taking a metal at its fusing-point as standard of light, a suggestion which I made at the International Congress of Electricians in Paris in 1881.

Preliminary investigations having established the constancy of the radiation during the solidification, I was able to attempt with certainty the realization of the absolute standard.

I take as absolute unit of light the radiation from the surface of 1 square centim. of platimum at its solidifying-point.

In order to get a definite multiple of the unit it is sufficient to increase the surface.

The Carcel lamp of Dumas and Regnault's pattern having been adopted as the usual secondary standard, I endeavoured in the first place to settle its ralue compared with my principal standard. $\mathrm{By}$ various methods, which closely agreed, I found for the value of the standard Carcel lamp C,

$$
\mathrm{C}=\frac{1}{2 \cdot 08}
$$

from which, taking the surface into account, it is concluded that the intrinsic intensity of our standard is almost eleven times that of the Carcel lamp.

I also worked with electrical foci. The comparison with our standard was found to be satisfactory in practice. I shall merely adduce experiments with incandescent lamps, the constancy and colour of which render the comparison with platinum easy and certain.

A Swan lamp was fed by a battery of thirty Kabath accumulators. By means of a resistance-box in the circuit, the conditions could be varied. An observer noted each minute the strength of the current $i$, and the fall of the potential between the terminals of the lamp. It was only necessary therefore to take the photometric measurement, and note the corresponding condition of the lamp, to get its illuminating-power E, special experiments made at the beginning and end of each series having established this illuminating-power for different values of $i e$. The relative values of $\mathrm{E}$ given below are independent of possible variations of Carcel's lamp.

In order to compare the electric lamp with the standard, a Bunsen's photometer was used which could be moved about between the two sources, which were at a distance from each other of 4 metres. The rays emitted by the platinum being directed horizontally by means of a wirror of $45^{\circ}$, the total effective distance was about 4.54 metres. It was each time determined exactly; we shall denote it by $\Delta$, and shall call $D$ the distance of the platinum from the photometer.

In the first set of experiments three different observers made each six measurements. Of the eighteen determinations thus 